\title{
Nursing Care to Newborns with Respiratory Distress Syndrome in Intensive Care Unit

\begin{abstract}
Larissa Mendonça Torres' ${ }^{1}$, Anelly Barbara Feitosa de Paiva ${ }^{2}$, Antônia Emanuella Oliveira Diniz ${ }^{2}$, Brenda Carla de Oliveira Moreira ${ }^{2}$, Yanna Gomes de Sousa ${ }^{3}$, Soraya Maria de Medeiros ${ }^{3}$, Jovanka Bittencourt Leite de Carvalho ${ }^{3}$
\end{abstract}

\section{Abstract}

Objective: To identify the main procedures performed by nursing staff to newborns with respiratory distress syndrome.

Methods: A descriptive study of qualitative approach, conducted through semi-structured interviews with seven nurses in the Neonatal Intensive Care Unit. The data collection was conducted from August to October 2015. For data analysis, content analysis was used.

Results: The identified units of meaning were grouped into three categories: nursing care for newborns affected by respiratory distress syndrome; primary care and procedures performed by nursing to the newborn affected by respiratory distress syndrome; difficulties of nursing for the care of that patient.

Conclusion: It is concluded that the overload of activities, the reduced number of staff, lack of materials, equipment and the need for professional development are the nurse's work reality in this sector. It was noticed a strong and responsible staff with apparent problems, but it was trying to elucidate their work and allowing to pull them away from work overload and structural difficulties in the area.

\section{Introduction}

Although the Respiratory Distress Syndrome to the Newborn (RDS$\mathrm{NB})$, also known as Hyaline Membrane Disease (HMD) or Respiratory Distress Syndrome (RDS), does not have a precise definition, it can be conceptualized as a clinical, laboratory and radiological syndrome
1 Department of Nursing, Federal University of Rio Grande do Norte, Natal, Rio Grande do Norte, Brazil.

2 Nursing School, Potiguar University, Mossoró, Rio Grande do Norte, Brazil.

3 Department of Nursing, Federal University of Rio Grande do Norte, Natal, Rio Grande do Norte, Brazil.

Contact information:

Larissa Mendonça Torres.

झ" larissatorres_@hotmail.com

Keywords

Respiratory Distress Syndrome; Newborn; Neonatal Intensive Care Unit; Nursing care. 
associated with pulmonary immaturity and the ribcage and surfactant deficiency. [1, 2]

Progressive and high-frequency respiratory insufficiency, breathlessness due to immaturity and atelectasis of the lungs characterize the RDSNB. It is reported that although it has been linked to a qualitative and quantitative dysfunction of the pulmonary surfactant system, its replacement has been associated with a sustained improvement in lung function and a reduction in the mortality rate [3].

Clinical manifestations of RDSNB have varying degrees of tachypnea, nasal flaring, retractions, moaning, and cyanosis. Apnea can occur secondary to hypoxemia and respiratory failure. In more severe cases, with disseminated micro atelectasis, there is a reduction of vesicular murmur [4].

When the RDSNB is untreated, it can lead to other major problems and in some cases, it can even be fatal. The RDSNB is highlighted in neonatal mortality rates. About $60 \%$ of newborn with less than 30 weeks of gestational age will develop this disease, and also approximately 5\% over 37 weeks. Pulmonary structures are no longer filled with liquid to become airy spaces and with gas exchange and they need to adapt to a thermally unstable environment and different metabolic activity of intrauterine [5].

Facing the severity of RDSNB picture, intensive care for newborns affected by this disease are needed. Thus, the Neonatal Intensive Care Unit (NICU) is an appropriate therapeutic environment for the treatment and rehabilitation of newborns (NB). [6]

Concerning to nursing, one of the most important functions is to observe the child's answer to therapy. NB's care aims to prevent and correct hypoxemia, correct changes as hypothermia and metabolic acidosis, prevent the synthesis of surfactant, maintain homeostasis, as it enables the lung recovery to synthesize lecithin surfactant; and prevent progressive alveolar atelectasis through the use of CPAP or respirator [7].
With this, we have developed as the research question: What are the nursing care for newborns with RDS in NICU?

This study was performed based on the need to understand the activities and care in nursing assistance in the NICU on patients with RDS, and their specificities, seeking insight and contribution to nursing in the recovery/promotion of the patient.

The choice of the research topic emerged from the affinity of the authors with the areas involved, Intensive Care Unit and Neonatology. The interest in RDSNB was after bibliographical research when it was necessary to research a disease that is affecting the newborns but having greater relevance than others.

\section{Methods}

Descriptive, exploratory and qualitative research conducted in Northeast Brazil in the city of Mossoró, reflecting on the nurse's role in the neonatal intensive care unit, seeking to understand the nurses who care for newborns in the NICU from their individual action.

There were seven nurses interviewed who work in NICU of a public hospital, not having the Baby-Friendly Hospital certification or implement the Kangaroo method systematically, although encouraging the skin to skin contact between parents and newborn.

Inclusion criteria were to work in the NICU and be an employee in the hospital for at least six months. Nurses who were on leave, vacation or the position vacant during the time of the survey were excluded from the study.

The interviews were conducted at a time and place chosen by the nurses from August to October 2015. Data collection was conducted through semistructured interviews.

Data analysis was performed through content analysis that consists of a research methodology to describe and interpret the content of all kinds of 
documents and texts8. As a research method, there were special procedures for processing scientific data. It can be considered as a single instrument adaptable to a very wide field of application.

The study was submitted to the Research Ethics Committee (REC) and approved under number CAAE 34057414.9.0000.5296.

\section{Results and Discussions}

Data were grouped into categories, considering the discussion of nursing care in the NICU to newborns with RDS. Interviews were conducted with the nurses of the NICU, who had a code to preserve their identities, described in the table below:

\section{Featuring the research subjects}

Only one nurse out of seven was specialized in neonatology. Only two of them have the necessary experience according to RDC 50/2009 - ANVISA9 to work in the area. Disqualification of six nurses on the specific neonatology does not make poor the sector of service quality developed by these nurses. They can provide the agile and competently service, bringing the best they can. (Table 1)
Table 1. Featuring the research subjects

\begin{tabular}{|l|l|l|r|r|}
\hline Subject & Category & $\begin{array}{c}\text { Professional } \\
\text { practice } \\
\text { time }\end{array}$ & $\begin{array}{r}\text { Professional } \\
\text { performance } \\
\text { time of } \\
\text { the search } \\
\text { service }\end{array}$ & $\begin{array}{c}\text { Specialist } \\
\text { in } \\
\text { neonatology }\end{array}$ \\
\hline E1 & Nurse & 1 to 5 years & 1 year & No \\
\hline E2 & Nurse & 1 to 5 years & $\begin{array}{c}0 \text { to } 6 \\
\text { months }\end{array}$ & No \\
\hline E3 & Nurse & 6 to 10 years & 1 to 5 years & No \\
\hline E4 & Nurse & 1 to 5 years & 1 years & No \\
\hline E5 & Nurse & 1 to 5 years & 1 years & No \\
\hline E6 & Nurse & 1 to 5 years & 1 years & No \\
E7 & Nurse & 1 to 5 years & 1 to 5 years & Yes \\
\hline
\end{tabular}

The guiding questions of the study subject allowed the development of three categories: nursing care for newborns affected by RDS; primary care and procedures performed by nursing to the newborn affected by RDS; difficulties of nursing during care of that patient.

Initially, professionals were asked on what is the contribution of nursing to NB affected by RDS. After the answers, categories of speeches were generated: Improvement of the respiratory pattern, Teamwork and Guiding and hosting. (Table 2)

Table 2. Nursing care of the newborns affected by RDS.

\begin{tabular}{|c|c|}
\hline Categories & Speeches \\
\hline \multirow{5}{*}{$\begin{array}{l}\text { Breathing } \\
\text { pattern } \\
\text { improvement }\end{array}$} & Proper positioning of the baby and oxygen supply necessary for the breathing pattern. E1 \\
\hline & ...monitoring oxygen saturation and evaluation of NB's chest dynamic as the discomfort and tachypnea. E2 \\
\hline & Encourage the appropriate oxygen therapy route and perform heating, decubitus, aspiration... E3 \\
\hline & $\begin{array}{l}\text {...nursing care directly contributes in controlling the amount of oxygen supplied, observing the parameters } \\
\text { of vital signs according to electronic monitors of neonatal ICU... E5 }\end{array}$ \\
\hline & $\begin{array}{l}\text {...the nursing contribution to RDS patients is intense, we evaluated the breathing pattern every two hours } \\
\text { and respiratory distress and qualify this pattern. E6 }\end{array}$ \\
\hline \multirow{4}{*}{ Teamwork } & $\begin{array}{l}\text {...we work in an interdisciplinary way with doctors, physiotherapists and other professionals in the nursing } \\
\text { field, and each of them contributes to improvement NB's clinical. Teamwork is harmonious and without } \\
\text { conflict. E2 }\end{array}$ \\
\hline & $\begin{array}{l}\text {...every professional within his specialty contributes to successful treatment and restoring the health of the } \\
\text { newborn... E4 }\end{array}$ \\
\hline & As a multidisciplinary team, we have each other. So, we need all working harmoniously. E5 \\
\hline & $\begin{array}{l}\text {...interdisciplinary work is very important, clinical evaluation is performed continuously, and the team is fully } \\
\text { interconnected. E7 }\end{array}$ \\
\hline
\end{tabular}




\section{Categories}

we are concerned to provide basic guidance to families to what it is allowed in the NICU, and guide about Guidance and Reception

\section{Speeches}

the equipment we are using the in baby and why... E4

The guidance to families consist of proper attire neonatal ICU hand hygiene and how to go to the baby bed. We explained about the current clinical status of the baby and care about discharge from the NICU...E3 ... guide (father and mother) about baby care and routine care of the neonatal ICU... E5

Source: Built from the semi-structured interview
We can see that the RDS assistance, the primary practice is the provision of adequate oxygen because the disease is characterized by progressive respiratory failure and often breathlessness due to atelectasis and immaturity of the lungs.

For the improvement of the NB, the nurses of this study mentioned that it is necessary not only to achieve the ideal oxygen therapy, but also other basic care to assist these infants such as handling, checking the oxygen saturation and vital signs.

In addition to the care and procedures, it is important to evaluate the quality of nursing care in an intensive care unit. This quality is based on the planning and organization of the service, following standards set out in documents governing this hospital service. These authors emphasize planning as a possibility to transform reality, involving issues such as management, participation, human resources and transformation [10].

Promoting care in the ICU requires nurses knowledge and responsibility. Care should be permeated by technology, especially for severe cases in infants. Also, to the competence, information integrations, construction judgments and priorities setting are required to the nurse, providing a homeostatic condition in both the biological and the psychological care [11].

A study conducted in the United States highlights the neonatal nurse as the mainstay of the NICU. The nurse is the person who works together with the doctor in the decision conducting treatment, performing direct neonatal care and offering emotional support to families. [12]

During the interviews, the nurses reported the importance of teamwork and how may be a facili- tator for assistance. Teamwork is the set or group of people with complementary skills committed to each other for the mission and objectives obtained by negotiation between the actors involved and a work plan in common [13].

In this context, the integrated work of the multidisciplinary team involved in the NB's care should include the medical and nursing staff, physiotherapists, speech therapists and social workers and psychologists specialized services. This is an important factor for the success of the recovery of this parent - child relationship and assist in the parents' relationship with the team linked in caring for the NB.

It was perceived and reported by the interviewees that the critical state of NBs admitted to the NICU makes a hostile and terrifying unit environment, bringing pain, insecurity, fear of losing the baby in the family and other provoked feelings in the mother and the father. From this, guidance and assistance are necessary, so they start to know the situation of the NB and have more security in the staff and hope in the baby's health [14].

The participation of the mother/father in the care of premature children is still incipient, but there is the interest of the health team in implementing it because they recognize the importance to promote clinical stability of premature and growth and development process. Also, it allows mother-child interaction and affective bonding, as well as the mother's training for the baby's discharge [1].

From the questions on the main care and procedures performed by nursing to the NB affected by RDS, the categories emerged were handling, Saturation, Oxygen therapy and Vital Signs. 
Table 3. Major care and procedures performed by nursing staff to the newborn affected by RDS..

\begin{tabular}{|c|c|}
\hline Categories & Speeches \\
\hline Saturation & ...The position must be appropriate because it directly affects the respiratory pattern of the baby..." E1 \\
\hline \multirow{2}{*}{ Saturation } & $\begin{array}{l}\text {...to monitor the oxygen saturation, nursing professionals must watch the level of oxygen and the baby chest } \\
\text { dynamics. E7 }\end{array}$ \\
\hline & $\begin{array}{l}\text {...in the nursing care, it is observed tachypnea, bradypnea, and eupeneia presented in the baby. Thus, it } \\
\text { promotes continuous evaluation with the interdisciplinary team. E2 }\end{array}$ \\
\hline \multirow{4}{*}{$\begin{array}{l}\text { Vital } \\
\text { signs }\end{array}$} & ...we offer the right amount of oxygen to the NB as prescription E1 \\
\hline & $\begin{array}{l}\text { The main nursing care are aimed at improving NB's breathing pattern. Along with the physical therapist, we } \\
\text { perform the posture changes needed to the respiratory baby pattern... E2 }\end{array}$ \\
\hline & $\begin{array}{l}\text { Nursing care involve actions such as heating, change of position, suction and stimulation of appropriate } \\
\text { oxygen pathway because the baby fatigues with an intense discomfort... E3 }\end{array}$ \\
\hline & $\begin{array}{l}\text {... Giving oxygen as prescription and work with physical therapy to evaluate the respiratory part of the } \\
\text { baby... E7 }\end{array}$ \\
\hline \multirow{2}{*}{ Vital signs } & ...to evaluate the baby worsening signs and the level of comfort..." E4 \\
\hline & ...to control pain and temperature... E2 \\
\hline
\end{tabular}

Source: Building from the semi-structure interview.

Within the nursing contributions in the service and the RDS of patients, we can highlight how is the assistance to the NB's family when admitted to the NICU, the hosting, how they are received and what procedures they also have contact and know how to deal with the situation of their babies. (Table 3)

On the answers given by respondents, we can perceive the nursing effort to provide quality care and meeting all the needs of patients and their families. All the interviewees spoke of the importance of nursing care for these newborns.

Nursing actively participates in all stages of the health-disease process, performing several essential procedures to improve them. Among the most cited, there are heat the NB, change in posture, aspiration, oxygen therapy, antibiotic therapy, venous access, always watching the oxygen saturation, the chest dynamics, the breathing pattern and this was evident in the speeches of most nurses.

The nurse is responsible for promoting the adaptation of the NB to the external environment (maintaining proper heat balance, the amount of moistu- re, light, sound and cutaneous stimulation). It is up to him to observe the clinical picture (monitoring of vital signs and special assistance procedures), provide adequate food to meet the metabolic needs of the body systems in development (if possible, breastfeeding) [15]. They should also carry out infection control, stimulate the NB, educate parents, encourage family visits, establish and maintain an educational plan, organize, manage and coordinate nursing care to the newborn and the mother.

In addition to the biological vulnerability of premature and low birth weight, the risks arising in the therapeutic process in neonatal intensive care units are the use of highly complex procedures and prolonged hospital stay, becoming susceptible children to infections and other diseases [16]. These situations raise more social and emotional costs of the family because they involve great human suffering, and thus the prematurity and low birth weight are considered a public health problem.

Professionals were also asked what difficulties of nursing for the care of that patient they have. When replying, the categories generated from the spee- 
Table 4. Difficulties of nursing for the care of this patient.

\begin{tabular}{|c|c|}
\hline Categories & Speeches \\
\hline \multirow[t]{2}{*}{ Resources } & $\begin{array}{l}\text { The main difficulties of nursing care in the NICU focus on instrumental and rigging... the incubator } \\
\text { sometimes is damaged, because they heat, the oximeter is broken not reading saturation, the fan sometimes } \\
\text { does not have a valve. E3 }\end{array}$ \\
\hline & $\begin{array}{l}\text { There are consumables; we have problems in maintaining equipment, vacuum cleaners and even the } \\
\text { network of oxygen, and this influences the quality of nursing care. E4 }\end{array}$ \\
\hline \multirow{3}{*}{$\begin{array}{l}\text { Work } \\
\text { overload }\end{array}$} & $\begin{array}{l}\text {...the lack of professionals in other specialties, for example, physiotherapist } 24 \mathrm{~h} \text { overloads the nursing staff } \\
\text { as just taking some functions that were performed by other professionals in the NICU E1. }\end{array}$ \\
\hline & ...What overloads nursing is the insufficient number of workers in night shifts... E5 \\
\hline & $\begin{array}{l}\text { Occupational overload comes from insufficient nursing professionals and other specialties in the NICU. There } \\
\text { are ten beds for a single nurse that besides the bureaucratic records, he must do the technical part of the } \\
\text { nursing procedures... E6 }\end{array}$ \\
\hline $\begin{array}{l}\text { Assistance } \\
\text { domain }\end{array}$ & $\begin{array}{l}\text { I see the lack of training promoted by the hospital management, many nursing technicians and nurses } \\
\text { without specific training to work in neonatal ICU...as difficulties in nursing care E2 }\end{array}$ \\
\hline
\end{tabular}

Source: Built from the semi-structure interview.

ches can be identified: Material resources, Work overload, Assistance domain. (Table 4)

In the interviews, the nurses said that the shortage of material resources is one of the greatest difficulties of the nursing staff because they often fail to provide quality care for the lack of some necessary material.

To perform a comprehensive care, trained professionals are not only required, but also a place with a good infrastructure that can accommodate patients in a dignified way and especially specific materials and equipment to the various procedures performed in the NICU [17].

The interviewees also brought difficulties to the workload of the nursing team, which is related to a large number of procedures performed, including surveys, aspiration, dressing, medication administration, care and feeding the NB. Most of them reported that the lack of physiotherapist at night further increases the workload of the nursing teamwork, they are responsible for all the care of newborns.

Faced with the answers, it can be seen that the nurse in the NICU not only carry out his work, but also activities related to technical, physiotherapists so that there is work overload.
The work in NICU is complex and intense, and the nurse has to be prepared for any time seeing patients with significant hemodynamic changes, which require specific knowledge and great ability to make decisions and implement them in a timely way [18].

In the context of quality of health services in general and, in particular, the ICU, nursing assumes a prominent role due to constitutes the largest group of health professionals as well as for maintaining daily and continuous contact with the patient, promoting the maintenance, recovery and rehabilitation of health through care and may influence the judgement on patients' quality of service. It is concluded that the nursing workload in the NICU is one of the main factors contributing to patient safety.

It is evidenced in the minimum staff requirements, reported in the DRC 50/2009 - ANVISA [9] the need for two nurses to ten daily beds in the NICU. The unit does not understand this necessary and perceptual composition nursing has to overcome its limitations to handle a complex and intensive service that requires too much of their time.

Not meeting this structure and not entailing what is right and considering that all the surveyed are 
women, and the female condition that also they have other activities at home, there is a synergism among the duties of this professional who can provide stress [19].

Another difficulty reported by one of the interviewees was about the level of knowledge. During the research, it was seen that most of the nurses did not have expertise in the neonatology field.

It is interesting that we can provide continuing education, assisting the teaching/learning as the nursing process and not only training but to be a nurse's right to specialize in the area the nurse is assisting. In this way, there will be a better offer of more quality to patients and have more security in their contributions by encouraging staff who have consistently corresponded to what is imposed on daily activities.

The proposed educational incentive to the public contractor agency could offer a better professional career and benefit the unit.

The Pan American Health Organization (PAHO) considers continuing education as an ongoing process that begins after the basic training and is intended to update and improve the ability of a person or group, in the face of technical and scientific developments and social needs.

As seen in this study, there is a part of the nursing team that believes not able to provide nursing care to risk newborns, and in that sense, there is a concern for creating a continuing education service for all who are part of this team. In health institutions, nursing services, an integral part of organizations come including the need to promote educational opportunities for its staff, to improve nursing practice [20].

Nurses' work is essential because it unites the scientific knowledge to the reality and practice of NICU. Indeed, it can recognize the baby's needs and plan their assistance [21]. It is important to note that while researchers were unable to complete the effectiveness of the work performed by nurses in the NICU, there are limitations and difficulties in their routine work.

\section{Final Considerations}

This study proposes an analysis of care and the role of nurses in the NICU in their care practice to NB, who develop RDS. It was possible to see and show the main care and contributions to the nursing team performing in the sector.

From the results of nursing care, it is necessary to expand the technological resources and ICU equipment maintenance, increasing the number of professionals working in the sector and promoting continuing education, that will enable nurses to provide technique quality care.

Through the testimonies of the nurses, it was learned that the work environment experienced by them in the NICU presents work overload, lack of materials, difficulty of teamwork for this to be reduced and the lack of continuing education. Nevertheless, we can see a strong nursing staff and very responsible with apparent problems, but trying to elucidate their work and allowing to pull away from work overload and structural difficulties in the area, which do not include all the assumptions and clarified guidelines in ordinances and RDCs and regulating intensive care units.

It is necessary a continuous work of the nursing staff to sensitize hospital managers about the importance of nursing care given to newborns hospitalized in an NICU for their survival.

\section{References}

1. Barbosa AL, Campos ACS, Chaves EMC. Non Clinical complications of mechanical ventilation in newborns: nursing care. Acta paul. enferm. 2006; 19(4): 439-43. Available on: http://www.scielo.br/scielo.php?script=sci_arttext \&pid=S010321002006000400012

2. Carvalho GC, Silveira RC, Procianoy RS. Ventilator-induced lung injury in preterm infants. Rev Bras Ter Intensiva. 2013; 25(4): 319-26. Available on: http://www.scielo.br/pdf/rbti/v25n4/ en 0103-507x-rbti-25-04-0319.pdf 
3. Hyaline membrane disease: the use of surfactant in this pathology. International Meeting of Scientific Production. Cesumar, October 23rd to 26th 2007. Available on: http://www.unicesumar.edu.br/prppge/pesquisa/epcc2007/ anais/tania mara gameiro rodrigues.pdf

4. Miyoshi MH. Brazilian consensus on mechanical ventilation in respiratory distress syndrome of the newborn. 2008. Available on: http://www.sbp.com.br/pdfs/Suporte ventilatorio sindrome desconforto respiratorio recem-nascido.pdf

5. Nascimento Júnior FJM, Silva JVF, Ferreira ALC, Rodrigues APRA. The respiratory distress syndrome of the newborn: pathophysiology and care challenges. Rev Ciências Biológicas e da Saúde. 2014; 2(2): 189-98. Available on: https://periodicos. set.edu.br/index.php/fitsbiosaude/article/view/1836/1054

6. Montanholi LL, Merighi MAB, Jesus MCP. Nurse's acting in the neonatal intensive care unit: between the ideal, the real and the possible. Rev. Latino-Am. Enfermagem. 2011; 19(2): [08 screen]. Available on: http://www.scielo.br/pdf/rlae/v19n2/pt 11

7. Queiroz NA, Maranhão DG. Actions and nursing care in the implementation of Kangaroo Mother Care. Rev Enferm UNISA. 2012; 13(2): 121-5. Available on: http://www.unisa.br/ graduacao/biologicas/enfer/revista/arquivos/2012-2-08.pdf

8. Moraes R. Content Analysis. Revista Educação. 1999; 22(37): 7-32, 1999. Available on: http://cliente.argo.com.br/ mgos/ analise de conteudo moraes.html

9. Ministry of health (BR). Resolution - RDC N. 50, February 21st, 2002. National Health Surveillance Agency - Brasília-DF, 2002.

10. Silva ND, Vieira MRR. Nursing team performance in the assistance of a high-risk neonate in a teaching hospital. Arq Ciênc Saúde. 2008; 15(3):110-6. Available on: http://repositorio-racs.famerp. br/racs_ol/vol-15-3/IDN273.pdf

11. Rolim KMC, Cardoso MVLML. Discourse and practice of care to newborns at risk: reflecting about humanized care. Rev Latinoam Enfermagem. 2006; 14(1):85-92. Available on: http://www. scielo.br/pdf/rlae/v14n1/v14n1a12.pdf

12. Hendricks-Munoz KD, Prendergast CC. Barriers to provision of developmental care in the neonatal intensive care unit: neonatal nursing perception. Am J Perinatol. 2007; 24(2):71-7. Available on: http://www.ncbi.nlm.nih.gov/pubmed/17260329

13. Kurcgant $P$, Ciampone MHT. Research in Nursing Administration area in Brazil. Rev Bras Enferm. 2005; 58(2):161-64.

14. Gaiva MAM. Care in neonatal intensive care units: searching for an ethical and humanized care. Rev. Cogitare Enferm. 2006; 1(1):61-65.

15. Souza KMO, Ferreira SD. Humanized attention in neonatal intensive-care unit: senses and the limitations identified by health professionals. Ciência \& Saúde Coletiva. 2010; 15(2):47180. Available on: http://www.scielo.br/scielo.php?script=sci art text\&pid=S1413-81232010000200024

16. Viegas D. Psychological aspects of care newborn. In: Viegas D, Vilhena-Moraes R. Neonatology: surgical clinic. Rio de Janeiro: Atheneu; 1989. p.276-91
17. Scochi CG. The humanization of hospital care for the premature baby: theoretical basis for nursing care [thesis]. Ribeirão Preto: Escola de Enfermagem de Ribeirão Preto, Universidade de São Paulo; 2000.

18. Gaidzinski RR, Fugulin FMT, Castilho V. Dimensioning of nursing staff in health institutions. In: Kurcgant $P$, coordinator. Nursing Administration. Rio de Janeiro: Guanabara Koogan; 2005. p.125-37.

19. Rolim KMC, Pagliuca LMF, Cardoso MVLML. Analysis of humanistic theory and interpersonal relationships of nurses in newborn care. Rev Latino-am Enfermagem 2005;13(3):432-40 Available on: http://www.scielo.br/pdf/rlae/v13n3/v13n3a19.pdf

20. Martinez JG, Fonseca LMM, Scochi CGS. The participation of parents in the care of premature children in a neonatal unit: meanings attributed by the health team. Rev Latino-am Enfermagem 2007;15(2):239-46 Available on: http://www. scielo.br/pdf/rlae/v15n2/pt v15n2a08.pdf

21. Oliveira MAN. Management of new technologies in surgical centers by nurses in hospitals in Feira de Santana -BA [dissertação]. Florianópolis: Universidade Federal de Santa Catarina; 2002

22. Kimura AF, Yoshitake APM, Bueno M, Belli MAJ. Assessment of the newborn respiratory function in the immediate neonatal period. Rev. Bras. Enferm. 2009; 62(6):850-55. Available from: http://www.scielo.br/pdf/reben/v62n6/a08v62n6.pdf

Publish in International Archives of Medicine

International Archives of Medicine is an open access journal publishing articles encompassing all aspects of medical science and clinical practice. IAM is considered a megajournal with independent sections on all areas of medicine. IAM is a really international journal with authors and board members from all around the world. The journal is widely indexed and classified Q1 in category Medicine. 